\title{
Heat Exchanger Network Optimization Considering Pressure Drop Constraints based on Minimum Operating Cost
}

\author{
http://dx.doi.org/10.3991/ijoe.v9iS6.2798 \\ L. Zhao ${ }^{1}$, Z. Huo ${ }^{2}$ and H. Yin ${ }^{1}$ \\ ${ }^{1}$ Dalian University of Technology, Dalian, China \\ ${ }^{2}$ University of Science and Technology LiaoNing, Anshan, China
}

\begin{abstract}
Considerable research effort has been reported in cost-optimal operation of heat exchanger network. However, most of them neglect the pressure drop influence and assume constant film heat transfer coefficients. Pressure drop of streams are important influencing factors for the performance of heat exchanger network operation. In this paper, a general cost-optimal operation model considering pressure drop constraints and removing the assumption of constant film heat transfer coefficients is proposed. It is necessary to determine the pumping power cost required as part of operating cost function. The extended model is applied to one example taken from previous research, and the results prove that the proposed method can obtain more real optimization results for HEN operational optimization problems.
\end{abstract}

Index Terms-Heat exchanger network, Cost-optimal operation, Film heat transfer coefficient, Pressure drop.

\section{INTRODUCTION}

Large number of literatures has been done on heat exchanger network synthesis (HENS). Yee and Grossmann[1] proposed a mixed integer nonlinear programming (MINLP) model considering simultaneously utility cost, exchanger areas and selection of matches, which can explicitly handle the trade-off between the capital and running cost. To obtain robust and ease solution, several simplifying assumptions are made such as isothermal mixing, constant film heat transfer coefficients, single design condition, no stream bypass, etc. Further developments have been complete for near real industry problems based on stage-wise superstructure representation (Ponce-Ortega, et.al[2]; Frausto-Hernández et al.[3]; Verheyen \& Zhang[4]; Kaj-Mikael Björk \& Tapio Westerlund[5]).

Although the synthesis methods have been developed successfully for HEN, there is no guarantee that minimum annual cost and flexibility can satisfy ideal target, since synthesis and detail design are not conducted in the same stage. It is necessary to confirm best performance of HEN system after design confronting with different disturbances, such as supplying temperatures, flow rates, fouling, pressure drop allowance, etc. Researches on detailed simulation and operation optimization have to be focus on to figure out contradiction between design and real situations. Mathisen et al.[6] discussed bypass selection method of HEN for controlling all critical targets, without considering utility cost. Glemmestad et al.[7] proposed an optimal operation of HEN method considering both target temperatures and utility consumption minimized. Online optimization and control method was investigated by Aguilera \& Marchetti[8] which can serve to have preliminary solutions to optimization problem for manipulating system. Glemmestad et al.[9] presented robust optimal operation method of HEN considering self-optimizing control. However, most papers ignored maintenance cost and pumping cost during the operating charge. Mitigating fouling cost is concluded in operating cost for optimization of operating conditions by Rodriguez and Smith[10].

In this paper, the pumping cost resulting from pressure drop during HEN system is introduced into operation optimization model, based on stage-wise superstructure representation proposed by Yee and Grossmann. One simple example is studied to illustrate the proposed approach.

\section{MODEL DESCRIPTION}

\section{A. Unit model}

\section{Steady state model of heat exchangers:}

In this work, all exchangers are assumed the same type with a single shell pass and a single tube pass counter flow arranging. The P-NTU method is used to model heat exchangers. The outlet temperatures of streams are determined as follows:

Outlet temperature of hot stream

$$
T h^{\text {out }}=(1-(R)(P)) T \mathrm{~h}^{\text {in }}+(R)(P) T \mathrm{c}^{\text {in }} .
$$

Outlet temperature of cold stream

$$
T c^{\text {out }}=(P) T \mathrm{~h}^{\text {in }}+(1-P) T \mathrm{c}^{\text {in }} .
$$

Where $T h^{\text {out }}$ is outlet temperature of hot stream; $T c^{\text {out }}$ is outlet temperature of cold stream. $R$ is heat capacity rate ratio; $P$ is referred to as thermal effectiveness. $R$ and $P$ are formulated as follows:

$$
R=\frac{W_{\mathrm{c}}}{W_{h}}
$$

General formula

$$
P=\frac{1-\exp (N T U(1-R))}{R-\exp (N T U(1-R))} .
$$

For $R=1$ 


$$
P=\frac{N T U}{1+N T U}
$$

Where $W_{c}$ is heat capacity flow rate of cold stream; $W_{h}$ is heat capacity flow rate of hot stream; $N T U$ is defined as number of transfer units that can be shown as follow:

$$
\begin{gathered}
N T U=\frac{U \cdot A}{W_{c}} . \\
\frac{1}{U}=\frac{1}{h_{t}}+\frac{1}{h_{s}} .
\end{gathered}
$$

Besides thermal transfer model, pressure drop is also an important issue of a heat exchanger, which has to be considered properly in heat exchanger network operation. For an exit HEN system, pumps/compressors have already been installed. Therefore, maximum pressure drop of the whole stream through the HEN system is fixed up. Power cost is one key component of operating cost besides hot and cold utilities. The pressure drop in HEN system can be considered into economic operation. Polley et al.[15] developed a general relationship between frictional pressure drop and convective film heat transfer coefficients as follows:

$$
\Delta P=K A h^{m}
$$

Where $\Delta P$ is the pressure drop of exchanger, $A$ is heat transfer area and $h$ is the film heat transfer coefficient. Based on Bell-Delaware method, the derived equations are shown by Frausto-Hernández et al. as follows:

Tube side equation

$$
\begin{gathered}
\Delta P_{T}=K_{P T} A h_{T}^{3.5} . \\
h_{T}=0.023 \frac{k}{d_{i}}\left(\frac{d_{i} v \rho}{\mu}\right)^{0.8}\left(\frac{C_{p} \mu}{k}\right)^{\mathrm{n}} .
\end{gathered}
$$

Shell side equation

$$
\begin{gathered}
\Delta P_{S}=K_{P S} A h_{S}^{5.109} . \\
h_{s}=0.36 \frac{k}{\mathrm{~d}_{0}}\left(\frac{\mathrm{d}_{0} v \rho}{\mu}\right)^{0.55}\left(\frac{C_{p} \mu}{k}\right)^{1 / 3} .
\end{gathered}
$$

Where $S$ and $T$ stand for shell and tube. The parameters $K_{P T}$ and $K_{P S}$ depend on the geometry and physical properties of the streams.

$$
\begin{gathered}
K_{P T}=\frac{\phi^{4.5} d_{i}^{0.5} \mu^{1.833}}{(0.023)^{2.5} g_{c} F \rho k^{2.333} C p^{1.167}} \\
K_{P S j}=\left(\frac{67.062 \phi^{6.109}}{g_{c}}\right)\left(\frac{L_{t p}-d_{e}}{d_{e}}\right)\left(\frac{L_{t p} d_{0}^{1.109} \mu^{1.297}}{F \rho k^{3.406} C p^{1.703}}\right) .
\end{gathered}
$$

Where $\varphi$ is the correction factor; $\mu$ is the viscosity, $\mathrm{kg} / \mathrm{m} \cdot \mathrm{s} ; \rho$ is the density, $\mathrm{m}^{3} / \mathrm{kg} ; g_{c}$ is the gravity constant, $\mathrm{m}^{3} / \mathrm{kg} \cdot \mathrm{s} ; \mathrm{k}$ is the thermal conductivity, $\mathrm{W} / \mathrm{m} \cdot{ }^{\circ} \mathrm{C} ; C p$ is the heat capacity, $\mathrm{J} / \mathrm{kg} \cdot{ }^{\circ} \mathrm{C} ; L_{t p}$ is tube pitch, $\mathrm{m} ; v$ is velocity of streams, $\mathrm{m} / \mathrm{s} ; d_{i}$ is the internal diameter of the tubes and $d_{e}$ is the external diameter of the tubes, $\mathrm{m} ; d_{0}$ is equivalent diameter, $\mathrm{m} ; n$ is assigned to 0.4 when heated and to 0.3 when cooled.

\section{Bypass:}

Bypass is one important manipulated variable for target temperature during HEN system operation. Through the use of process exchanger bypasses, heat duty of heat exchangers and outlet temperature of streams can be changed indirectly. The bypass model can be formulated as follows:

$$
\begin{aligned}
& W_{\mathrm{b}}=(1-r) W, 0<r<1 . \\
& T^{\text {out }}=r T^{\text {in }}+(1-r) T_{b}^{\text {out }} .
\end{aligned}
$$

Where $r$ represents bypassed flow fraction of streams; $W_{\mathrm{b}}$ is heat capacity flow rate through heat exchanger.

\section{Splitter and mixer:}

The splitters and mixers are assumed setting in entry end and exit end of each stage respectively. All the branches in a stream are remixed before leaving the network. The mass and energy balance formulations are shown as follows:

For splitter:

$$
\begin{gathered}
W_{i}=r_{i} W . \\
\sum_{i=1} r_{i}=1
\end{gathered}
$$

For mixer:

$$
T^{\text {out }}=\frac{\sum_{i=1} W_{i} T_{i}^{\text {out }}}{W} .
$$

$$
\begin{gathered}
\sum_{i=1} W_{i}=W \\
T h^{\text {out }}=(1-(R)(P)) T \mathrm{~h}^{\text {in }}+(R)(P) T \mathrm{c}^{\text {in }} .
\end{gathered}
$$

\section{B. Stage-wise superstructure model}

This section provides a formulation of NLP optimal operation model based on stage-wise superstructure representation proposed by Yee and Grossmann. The general model involves heat balance for each stream, energy balance for each stage and each exchanger, mass balance and energy balance for splitter and mixer, logical constraints for temperatures and pressure drops. The aim of the NLP model is minimization of running cost consisting of utility cost and power cost.

Objection function:

$$
\min \left(\begin{array}{l}
\sum_{i=1}^{H N} c_{-} c u Q c_{i}+\sum_{j=1}^{C N} c_{-} h u Q h_{j}+ \\
\sum_{i=1}^{H N} c_{-} p F h_{i} \Delta P_{i}+\sum_{j=1}^{C N} c_{-} p F c_{j} \Delta P_{j}
\end{array}\right) .
$$


Constraint equations for pressure drops:

Total pressure drop of each stream

$$
\begin{aligned}
\Delta P_{i} & =\sum_{k=1}^{K N} \Delta P_{i, k} . \\
\Delta P_{j} & =\sum_{k=1}^{K N} \Delta P_{j, k} .
\end{aligned}
$$

Feasibility of pressure drop

$$
\begin{aligned}
\Delta P_{i} & \leq P M A X_{i} . \\
\Delta P_{j} & \leq P M A X_{j} .
\end{aligned}
$$

Nomenclature:

\section{Parameter}

$Q_{h}-$ Hot utility consumption, kW

$Q_{c}$ Cold utility consumption, kW

$P_{\text {MAX }} \longrightarrow$ Maximum pressure drop allowance of each stream, Pa.

$c_{\text {c cu }} \longrightarrow$ Per unit cost for cold utility, $\$ \cdot \mathrm{kW}^{-1}$

$c_{\text {hu }}$ Per unit cost for hot utility, $\$ \cdot \mathrm{kW}^{-1}$

$c_{\perp} \_$per unit cost for power, $\$ \cdot \mathrm{kW}^{-1}$

$F h-$ hot stream volume flow, $\mathrm{m}^{3} / \mathrm{s}$;

$F_{c} \_$cold stream volume flow, $\mathrm{m}^{3} / \mathrm{s}$;

Superscript

in - Inlet;

out — Outlet.

Subscript

$i-$ Index of hot stream;

$j-$ Index of cold stream;

$k-$ Index of stage.

\section{CASE STUDY AND DISCUSSION}

The example used in this work comes from the work of Glemmestad et al. The given HEN structure is shown in Fig. 1. The HEN superstructure is divided into two stages. E1 and E2 locate in stage 1 and stage 2 respectively. Hot fluid flow through tube side in E1 and flow through shell side in E2. As an optimal operation problem, there are three final controlled variables which are outlet temperature of $\mathrm{H} 1, \mathrm{C} 1$ and $\mathrm{C} 2$. Four manipulated variables of two bypasses, a heater and a cooler are used for guaranteeing target temperatures. Marselle et al.[12] defined the remaining degrees of freedom(NDOF), NDOF equals to number of manipulated variables minus number of controlled variables. If NODF is not less than zero, the operation of HEN is feasible and operating cost can be optimized. For this example, the NDOF is one so that minimum operating cost can be obtained through adjust manipulated variables. During the work of Glemmestad et al, film heat transfer coefficients of streams are given con- stant, no pressure drop constraints are considered during operation. To get closer to industrial reality, various heat transfer coefficients associated with heat capacity flow rate are incorporated into HEN model. For this reason, more physical property parameters of streams such as density, viscosity, specific capacity and thermal conductivity have to be complemented, which are supplied in Table 1. For the same reason, pressure drop analysis of exchangers is necessary for HEN. Pressure drop has a relationship with Geometries property of heat exchangers. Therefore, geometries information of heat exchangers are added shown in Table 2. The disturbances still take place in the $\mathrm{H} 1$ and $\mathrm{C} 2$. The inlet temperature of $\mathrm{H} 1$ and the heat capacity flow rate of C2 vary during operation. Five different operating cases are shown in Table 3. For simplicity, it is assumed that the utility heat exchangers are able to deliver sufficient duty for all possible cases.

The proposed method is applied in this example step by step obtaining the best operation project for different cases. First, target temperature and maximum pressure drop allowance must be guarantee for reasonable operation. $\Delta P_{\mathrm{H} 1}, \Delta P_{\mathrm{C} 1}$ and $\Delta P_{\mathrm{C} 2}$ represent the overall pressure drop of each stream through HEN, which is calculated by adding pressure drop of each unit located in the stream. The pumping cost is proportional to overall pressure drop. Two bypasses ratio and heat duty of heater and cooler are determined for minimized utility cost including power cost. Optimized results are shown in Table 4.

Physical property of streams and five different cases shown in Table 1 and Table 3 can be used to determine optimal operation for the aspect of constant heat transfer coefficient and without considering pumping cost. As can be seen in Table 5, the bypass ratio values are usually larger than the values considering non-uniform overall heat transfer coefficient in order to obtain cost-optimal operation. For case 1, the bypass ratio values are uniform because the UA are the same for two aspects. For other case $2, u_{1}$ is 0.105 in Table 5 and 0.0774 in Table 4, which results from the different UA value. It is obvious that the latter is near the real situation because the heat transfer coefficient is also influenced by uncertain input parameter. When supplying parameter of streams changes to another condition, UA has to be revaluated to obtain real heat transfer duty.

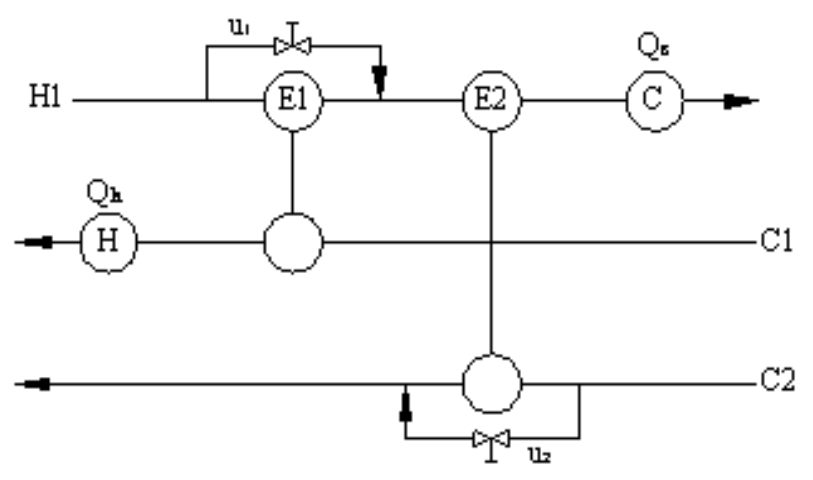

Figure 1. Structure of HEN 
SPECIAL FOCUS PAPER

Heat Exchanger Network Optimization Considering Pressure Drop Constraints based on Minimum...

TABLE I.

PHYSICAL PROPERTY FOR STREAMS

\begin{tabular}{|c|c|c|c|c|c|c|c|}
\hline Stream & $\boldsymbol{T}_{\text {in }}\left({ }^{\circ} \mathbf{C}\right)$ & $\boldsymbol{T}_{\text {out }}\left({ }^{\circ} \mathbf{C}\right)$ & $\boldsymbol{C}_{p}\left(\mathbf{J} / \mathbf{k g} \cdot{ }^{\circ} \mathbf{C}\right)$ & $\boldsymbol{W}\left(\mathbf{k J} /{ }^{\circ} \mathbf{C} \cdot \mathbf{s}\right)$ & $\boldsymbol{\rho}\left(\mathbf{k g} / \mathbf{m}^{3}\right)$ & $\boldsymbol{\mu}(\mathbf{k g} / \mathbf{m} \cdot \mathbf{s})$ & $\boldsymbol{k}\left(\mathbf{W} / \mathbf{m} \cdot{ }^{\circ} \mathbf{C}\right)$ \\
\hline H1 & 190 & 20 & 2600 & 30 & 0.114 & $0.24 \times 10^{-3}$ & 700 \\
\hline C1 & 80 & 160 & 2600 & 45 & 0.114 & $0.24 \times 10^{-3}$ \\
\hline C2 & 20 & 130 & 1000 & 15 & 600 & $0.24 \times 10^{-3}$ & 0.114 \\
\hline
\end{tabular}

Steam cost: 60 \$/kW/year; Water cost: $6 \$ / \mathrm{kW} /$ year; Power cost: $2 \$ / \mathrm{kW} /$ year

TABLE II.

DETAIL DATA FOR HEAT EXCHANGERS

\begin{tabular}{|c|c|c|c|c|}
\hline Exchanger & $\boldsymbol{A}_{\left(\mathbf{m}^{2}\right)}$ & $\boldsymbol{D}_{\mathbf{i}}(\mathbf{m})$ & $\boldsymbol{D}_{\mathbf{e}}(\mathbf{m})$ & $\boldsymbol{P}_{\mathbf{t}}(\mathbf{m})$ \\
\hline E1 & 22 & 0.017 & 0.019 & 0.0243 \\
\hline E2 & 86 & 0.017 & 0.019 & 0.0243 \\
\hline
\end{tabular}

TABLE III.

DATA OF DIFFERENT CONDITIONS

\begin{tabular}{|c|c|c|c|c|c|c|}
\hline Work condition & $\begin{array}{c}T_{\text {in }}(\mathrm{H} 1) \\
\left({ }^{\circ} \mathrm{C}\right) \\
\end{array}$ & $\begin{array}{c}W(\mathrm{H} 1) \\
\left(\mathrm{kJ} /{ }^{\circ} \mathrm{C} \cdot \mathrm{s}\right)\end{array}$ & $\begin{array}{c}T_{\text {in }}(\mathrm{C} 1) \\
\left({ }^{\circ} \mathrm{C}\right) \\
\end{array}$ & $\begin{array}{c}W(\mathrm{C} 1) \\
\left(\mathrm{kJ} /{ }^{\circ} \mathrm{C} \cdot \mathrm{s}\right)\end{array}$ & $\begin{array}{c}T_{\text {in }}(\mathrm{C} 2) \\
\left({ }^{\circ} \mathrm{C}\right) \\
\end{array}$ & $\begin{array}{c}W(\mathrm{C} 2) \\
\left(\mathrm{kJ} /{ }^{\circ} \mathrm{C} \cdot \mathrm{s}\right)\end{array}$ \\
\hline Case 1 & 190 & 30 & 80 & 45 & 20 & 15 \\
\hline Case 2 & 187 & 30 & 80 & 45 & 20 & 14.7 \\
\hline Case 3 & 187 & 30 & 80 & 45 & 20 & 15.3 \\
\hline Case 4 & 193 & 30 & 80 & 45 & 20 & 14.7 \\
\hline Case 5 & 193 & 30 & 80 & 45 & 20 & 15.3 \\
\hline
\end{tabular}

TABLE IV.

OPTIMIZATION RESULTS CONSIDERING NON-UNIFORM OVERALL HEAT TRANSFER COEFFICIENT

\begin{tabular}{|c|c|c|c|c|c|}
\hline Optimization results & Case1 & Case2 & Case3 & Case 4 & Case5 \\
\hline$u_{1}$ & 0 & 0.0774 & 0.1468 & 0 & 0 \\
\hline$u_{2}$ & 0 & 0 & 0 & 0.0251 & 0.0110 \\
\hline$Q_{c}(\mathrm{~kW})$ & 1951.3 & 1964.3 & 1935.8 & 2040.6 & 1974.6 \\
\hline$Q_{h}(\mathrm{~kW})$ & 2401.3 & 2471.3 & 2508.8 & 2367.6 & 2367.6 \\
\hline$\Delta P_{H 1}(\mathrm{kPa})$ & 1470.9 & 1393.1 & 1327.6 & 1470.9 & 1470.9 \\
\hline$\Delta P_{C 1}(\mathrm{kPa})$ & 7196.4 & 7196.4 & 7196.4 & 7196.4 & 7196.4 \\
\hline$\Delta P_{C 2}(\mathrm{kPa})$ & 5328.5 & 5007.7 & 5666.9 & 4631.2 & 5443.2 \\
\hline Pumping power $\operatorname{cost}(\$)$ & 671 & 647 & 688 & 631 & 682 \\
\hline Utility $\operatorname{cost}(\$)$ & 155773 & 160045 & 162146 & 154301 & 153904 \\
\hline Total operating $\operatorname{cost}(\$)$ & 156444 & 160692 & 162834 & 154932 & 154586 \\
\hline
\end{tabular}

TABLE $V$.

OPTIMIZATION RESULTS CONSIDERING CONSTANT OVERALL HEAT TRANSFER COEFFICIENT

\begin{tabular}{|c|c|c|c|c|c|}
\hline Optimization results & Case1 & Case2 & Case3 & Case4 & Case5 \\
\hline$u_{1}$ & 0 & 0.105 & 0.292 & 0 & 0 \\
\hline$u_{2}$ & 0 & 0 & 0 & 0.036 & 0.011 \\
\hline$Q_{c}(\mathrm{~kW})$ & 1951.1 & 1951.8 & 1948.4 & 2040.4 & 1974.4 \\
\hline$Q_{h}(\mathrm{~kW})$ & 2401.1 & 2458.8 & 2521.4 & 2367.4 & 2367.4 \\
\hline Total operating $\operatorname{cost}(\$)$ & 155773 & 159239 & 162974 & 154304 & 153908 \\
\hline
\end{tabular}

\section{CONCLUSION}

Most HEN operation optimization procedures reported assume heat transfer efficient constant and do not consider the pressure drop aspects of the problem. It is well-known that heat transfer efficient and pressure drop are important factors influencing the performance of HEN. The former can change heat duty of heat exchanger directly, which has a relationship with the latter. Besides influenced heat transfer rate, pressure drop means pumping power cost is required. A simple model based on stage-wise superstructure is proposed for optimal operation problem, which is extended by incorporating equations of heat transfer efficient and pressure drop during each heat exchanger network. The case study proves that the proposed method can obtain more real optimization results for HEN operational optimization problems.

\section{ACKNOWLEDGMENT}

This work was financially supported by the Fundamental Research Funds for the Central Universities.

\section{REFERENCES}

[1] T. F. Yee and I. E. Grossmann. "Simultaneous optimization models for heat integration-II. Heat exchanger network synthesis". Computers and Chemical Engineering, Vol. 14, Issue 10, 1990, pp. 1165-1184. http://dx.doi.org/10.1016/0098-1354(90)85010-8

[2] J. M. Ponce-Ortega, A. Jiménez-Gutiérrez, I. E. Grossmann. “Optimal synthesis of heat exchanger networks involving isothermal process streams". Computers and Chemical Engineering, Vol. 32, Issue $\quad 8, \quad 2008, \quad$ pp. 1918-1942. http://dx.doi.org/10.1016/j.compchemeng.2007.10.007

[3] S. Frausto-Hernández, V. Rico-Ramírez, A. Jiménez-Gutiérrez, S. Hernández-Castro. "MINLP synthesis of heat exchanger networks considering pressure drop effects". Computers and Chemical Engineering, Vol. 27, Issue 8, 2003, pp. 1143-1152. http://dx.doi.org/10.1016/S0098-1354(03)00042-5 
[4] W. Verheyen, N. Zhang. "Design of flexible heat exchanger network for multi-period operation”. Chemical Engineering Science, Vol. 61, Issue 23, 2006, pp. 7730-7757.

[5] K.-M. Björk, T. Westerlund. "Global optimization of heat exchanger network synthesis problems with and without the isothermal mixing assumption". Computers and Chemical Engineering, Vol. 26, Issue 11, 2002, pp. 1581-1593. http://dx.doi.org/10.1016/S0098-1354(02)00129-1

[6] K. W. Mathisen, S. Skogestad, and E. A. Wolffa. "Bypass selection for control of heat exchanger networks". Computers and Chemical Engineering, Vol. 16, Issue S1, 1992, pp. 263-272. http://dx.doi.org/10.1016/S0098-1354(09)80031-8

[7] G. Glemmestad, K. W. Mathisen and T. Gundersen. "Optimal operation of heat exchanger networks based on structural information". Computers and Chemical Engineering, Vol. 20, Issue S1, $1996, \quad$ pp. 823-828. $\quad$ http://dx.doi.org/10.1016/00981354(96)00145-7

[8] N. Aguilera and J. Marchetti. "Optimizting and controlling the operation of heat exchanger network". AIChE, Vol. 44, Issue 5, 1998, pp. 1090-1104. http://dx.doi.org/10.1002/aic.690440508

[9] B. Glemmestad, S. Skogestad, and T. Gundersen. "Optimal operation of heat exchanger networks". Computers and Chemical Engineering, Vol. 23, Issue 4, 1999, pp. 509-522. http://dx.doi.org/10.1016/S0098-1354(98)00289-0

[10] C. Rodriguez and R. Smith. "Optimization of operating conditions for mitigating fouling in heat exchanger networks". Chemical Engineering Research and Design, Vol. 85, Issue A6, 2007, pp. 839851. http://dx.doi.org/10.1205/cherd06046

[11] G. T. Polley, S. Panjeh and F. O. Jegede. "Pressure drop considerations in the retrofit of heat exchanger networks". Transactions of the Institute of Chemical Engineers, Vol. 68, Issue A, 1990, pp. 211-220.

[12] D. F. Marselle, M. Morari, and D. F. Rudd. "Design of resilient processing plants- II Design and control of energy management systems". Chemical Engineering Science, Vol. 37, Issue 2, 1982, pp. 259-270.

\section{AUTHORS}

L. Zhao is with the School of Energy and Power Engineering, Dalian University of Technology, Dalian 116023, China (e-mail: zldlut@163.com).

Z. Huo was the School of Energy and Power Engineering, Dalian University of Technology, Dalian 116023, China. He is now with the School of Materials and metallurgy, University of Science and Technology LiaoNing, Anshan 114051, China (e-mail: hzy10710010@ 163.com).

H. Yin is with the School of Energy and Power Engineering, Dalian University of Technology, Dalian 116023, China (e-mail: hcyin@dlut.edu.cn).

This work was financially supported by the Fundamental Research Funds for the Central Universities. It is an extended and modified version of a paper presented at the 2012 International Conference on Artificial Intelligence and Its Application in Industry Production (AIAIP 2012), held in Wuhan, China in December 2012. Manuscript received 14 May 2013. Published as resubmitted by the authors 26 June 2013. 